\title{
Status of AM Fungi in Some Medicinal Plants from Panambur Beach Mangalore India
}

\author{
${ }^{1}$ Vishal R. Kamble, ${ }^{2}$ Devarajan Thangadurai, ${ }^{3}$ Harshal L. Rahate and \\ ${ }^{4}$ Dinesh G. Agre \\ ${ }^{1,2-3}$ Department of Botany, Bhavan's College Andheri (West), Mumbai 400058 \\ ${ }^{4}$ Department of Botany, Karnatak University, Dharwad 580 003, Karnataka.
}

\begin{abstract}
Present study was undertaken to check the present status of AM fungi in four medicinal plants found in costal sand dune (CSD) habitat, from 'Panambur beach' situated in Dakshina Kannada District near

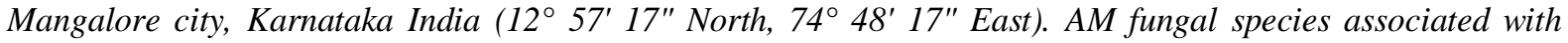
medicinal plants were belonging to three genera viz., Acaulospora, Gigaspora and Glomus representing 12 species.
\end{abstract}

Keywords: AM fungi, Coastal Sand dune, CSD, medicinal plants

\section{Introduction}

The costal biota is under serious threat from human activities that lead to destruction of natural ecosystem at an alarming rate. These has phenomenal increase in vegetation loss during last few decayed. The costal regions harbour many economic and medicinal plant species [3] [5]. The local community surrounding the coast depends upon these resources for their livelihood. They collect and utilize many plants for food, timber, fiber, fuel, and medicine. Their high utility, i.e. economic and medicinal, is an important contributing factor to their over exploitation. The continual use of costal plants over many years without these being replanted has resulted in accelerated decline in the abundance or the loss of a wide range of threatened and endangered species [4]. Herbal and traditional medicine in global market is fetching approximately US \$60 billion per annum with India's share about US \$ 400-500 million [15]. Due to biopiracy threat, detailed documentation of the untapped costal sand dunes (CSD) resources is of immense value. A wide range of microbes associated with belowground root biomass facilitates the dune stabilization [2]. Amongst the belowground root microbes Arbuscular mycorrhizal fungai (AM) are very significant for uptake of water and nutrients, especially in phosphorus deficient condition, and also help plant establishment in very harsh environments [22]. AM fungi are known to significantly contribute to the development of plant community structure and sand dune stabilization. Coastal sand dunes are of great ecological significance. They act as barriers against the action of waves and tides [1]. Hence, it is necessary to draw attention toward the association of AM fungi and CSD medicinal plants despite of the disturbed or undisturbed nature of dunes.

Most studies on AM fungi of coastal dunes are confined to temperate regions, and subtropical regions [17], a few were performed from the tropical coast of Hawaiian Islands [19] [21], India [12] [13] [24] [25] [26] [27] and Singapore [6]. In last decayed, Panambur beach was explored for AM fungal colonization, species richness and diversity associated with Ipomoea pes-caprae (L.) R. Br. (with less vegetation) in relation to rhizosphere edaphic features [13]. This study was carried out on severely disturbed dunes because of recreation and harbor activities on west coast of India particularly adjoining sites of Panambur beach. However, costal zone protection initiatives made in past few years has showed good results and this beach is now well maintained. Medicinal efficacy of more frequently growing beach plants viz., Canavalia rosea (Sw.) DC (Fabaceae), I. pes-caprae (Convolvulaceae), Launaea sermentosa (Willd.) Schult-Bip.ex O. Kuntze (Asteraceae) and Phyla nodiflora (L) Greene (Verbenaceae) is now well studied. A hot water infusion of the leaves of C. rosea with other used in Tonga to treat secondary amenorrho postpartum hemorrhage [28]. I. pescaprae leaves are usually used in colic, bedsores and in the treatment of ulcers [23]. It is also used in rheumatism and diuretic [10], gonorrhea skin diseases and stomachache [4]. L. sermentosa, whole plant juice is applied for the treatment of rheumatism [4], it also exhibit antimicrobial property [7] and used in renal disorders [18]. Fresh plant paste or poultice of P. nodiflora is applied for boils, swollen cervical glands and chronic indolent ulcers [4]. Thus these are some of the important medicinal plants of sandy beach habitat. Although, AM fungal study was made with I. pes-caprae from Panambur beach previously [13], in present study an attempt has made to check present status AM fungi in these medicinal plants found in addition to I. pes-caprae. 


\subsection{AM fungal colonization status}

\section{Material And Methods}

Root samples of medicinal plant species distantly growing approximately 100 meter away from each other were collected from Panambur Beach during July-Sept 2011 and brought to the laboratory. Roots were made free from sand and debris to process and stain [8] [20]. Stained roots were observed under a binocular microscope to evaluate mycorrhizal colonization [14].

\subsection{AM fungal species identification}

Spores were isolated from Rhizopheric sand of plant with the help of wet sieving and decanting method [9]. Spores with the same morphology were mounted in water, in polyvinyl-lactoglycerol (PVLG) and in PVLG with a drop of Mezler's reagent for microscopic examination. Spores mounted in Mezler's reagent were crushed in order to observe the staining of the different spore wall layers. At least 20 spores of each of the different morphotypes found were mounted in PVLG and 10 spores mounted in PVLG + Melzer's reagent for morphological identification after the original descriptions [16].

\section{Results And Discussion}

AM fungi were encountered in the roots of all plants studied from Panambur beach (Table 1, Fig. 1). All the mycorrhizal components (vesicles, arbuscules and hyphae) were found with variation in occurrence intensity in all plants viz., C. rosea, I. pes-caprae, L. sermentosa and P. nodiflora. Earlier studies reveals that, L. sermentosa exhibited $45 \%$ mycorrhizal colonization and $10 \mathrm{AM}$ spores $100 \mathrm{~g}^{-1}$ soil from Someshwara West Coast of India [11]. However, in present investigation we have reported $98 \%$ colonization and 80 AM spores $100 \mathrm{~g}^{-1}$ soil in L. sermentosa. I. pes-caprae showed drastic improvement in colonization percentage (100\%) in comparison with previous study (77.8\%) [13]. The spore count in rhizospheric sample was remarkable i.e., total $242 \mathrm{AM}$ spore $100 \mathrm{~g}^{-1}$ soil were recorded. The observed AM spore species associated with I. pes-caprae agree with earlier findings [13]. However, disappearance of some species was also noticed. The degree of AM fungal colonization was found almost closely similar in some of the plant species such as $98 \%$ colonization in C. rosea and $L$. sermentosa while I. pes-caprae and P. nodiflora exhibit 100\% colonization. Whereas, earlier study [13] showed that Canavalia cathartica and C. maritime were colonized at the rate of $83 \%$ and $24 \%$ respectively from Padubidri region of West coast of India. Although, P. nodiflora from Padubidri site in previous study [13] was reported non mycorrhizal, our observations proved that it has mycorrhizal association in present study area which is having similar geographical and climatic conditions like Padubidri. This study indicates the excellent pervasiveness of AM fungi is established in the root system of all four medicinal plants.

In present study, AM fungal species observed in rhizhosphere samples of CSD medicinal plants were belonging to three genera viz., Acaulospora, Gigaspora and Glomus which represents 12 species (Table 2). Some of these AM fungal spores are presented in Fig. 2. Most dominating spores of AM fungi in the sand samples from Panambur beach were: Acaulospora rehmii Sieverding and Toro, Acaulospora scrobiculata Trappe, Acaulospora spp, Gigaspora spp, Glomus aggregatum Schenk and Smith., Glomus caledonium (T.H. Nicolson \& Gerd.) Trappe \& Gerd, Glomus constrictum Trappe, Glomus fasciculatum (Thaxt.) Gerd. \& Trappe, Glomus flavisporum Tul. \& Tul., Glomus macrocarpum Tul. et Tul., Glomus microcarpus Tul. et Tul., and Glomus spp. Maximum spore count was reported in I. pes-caprae, whereas, remaining three plant species showed almost same spore count (Table 2). Our findings in present study, adds significant information to existing data and suggests that, Panmbur beach is nurturing some medicinal plants with good rate of mycorrhizal symbiosis.

TABLES

Table 1. Status of AM fungi in some medicinal plants from Panambur Beach

\begin{tabular}{|c|c|c|c|c|c|}
\hline \multirow[t]{2}{*}{ Sr No. } & \multirow[t]{2}{*}{ Medicinal plant species } & \multicolumn{3}{|c|}{$\begin{array}{c}{ }^{\#} \text { Occurrence intensity } \\
\text { of AM fungi }\end{array}$} & \multirow[t]{2}{*}{$\begin{array}{l}\text { Percentage } \\
\text { colonization }\end{array}$} \\
\hline & & $\mathbf{V}$ & $\overline{\mathbf{A}}$ & $\mathbf{H}$ & \\
\hline 1. & $\begin{array}{cccc}\text { Canavalia } & \text { rosea } & \text { (Sw.) } & \text { DC } \\
\text { (Fabaceae) } & & & \end{array}$ & ++++ & +++ & ++++ & $98 \%$ \\
\hline 2. & $\begin{array}{c}\text { Ipomoea pes-caprae (L.) R. Br. } \\
\text { (Convolvulaceae) }\end{array}$ & ++++ & + & ++++ & $100 \%$ \\
\hline 3. & $\begin{array}{llr}\text { Launaea sermentosa } & \text { (Willd.) } \\
\text { Schult-Bip.ex } & \text { O. } & \text { Kuntze } \\
\text { (Asteraceae) } & & \end{array}$ & ++++ & ++ & ++++ & $98 \%$ \\
\hline 4. & $\begin{array}{l}\text { Phyla nodiflora (L) Greene } \\
\text { (Verbenaceae) }\end{array}$ & ++++ & + & ++++ & $100 \%$ \\
\hline
\end{tabular}

\# [Vesicles (V); Arbuscules (A); Hyphae (H); (+)1-25\%: Poor; (++)25-50\%: Moderate; (+++)50-75\%: good; $(++++)$ more than $75 \%$ : Excellent.] 
Status Of AM Fungi In Some Medicinal Plants From Panambur Beach Mangalore India

Table 2. AM fungal species in some medicinal plants from Panambur Beach

\begin{tabular}{|c|c|c|c|c|c|}
\hline \multirow[t]{2}{*}{$\begin{array}{l}\text { Sr. } \\
\text { No. }\end{array}$} & \multirow[t]{2}{*}{ AM fungal species } & \multicolumn{4}{|c|}{$\begin{array}{l}\text { "Occurrence of AM fungal } \\
\text { spores in Medicinal plant } \\
\text { species }\end{array}$} \\
\hline & & $\mathrm{Cr}$ & Ip & $L s$ & $P n$ \\
\hline 1. & Acaulospora rehmii Sieverding and Toro & + & - & - & - \\
\hline 2. & Acaulospora scrobiculata Trappe & - & - & - & + \\
\hline 3. & Acaulospora spp & - & - & - & + \\
\hline 4. & Gigaspora spp & - & - & + & - \\
\hline 5. & Glomus aggregatum Schenk and Smith & - & - & + & - \\
\hline 6. & $\begin{array}{l}\text { Glomus caledonium (T.H. Nicolson \& Gerd.) Trappe \& } \\
\text { Gerd }\end{array}$ & - & + & - & - \\
\hline 7. & Glomus constrictum Trappe & - & + & - & - \\
\hline 8. & Glomus fasciculatum (Thaxt.) Gerd. \& Trappe & - & + & - & - \\
\hline 9. & Glomus flavisporum Tul. \& Tul. & + & - & - & - \\
\hline 10. & Glomus macrocarpum Tul. et Tul. & + & - & - & - \\
\hline 11. & Glomus microcarpus Tul. \&Tul. & - & - & + & - \\
\hline 12. & Glomus spp & + & - & - & - \\
\hline \multicolumn{2}{|c|}{ Total No. of AM Spores $100 \mathrm{~g}^{-1}$ rhizoshere sample } & 86 & 242 & 80 & 83 \\
\hline
\end{tabular}

* [Cr: Canavalia rosea; Ip: Ipomoea pes caprae; Ls: Launaea sermentosa; Pn: Phyla nodiflora; (+) present; (-) absent]

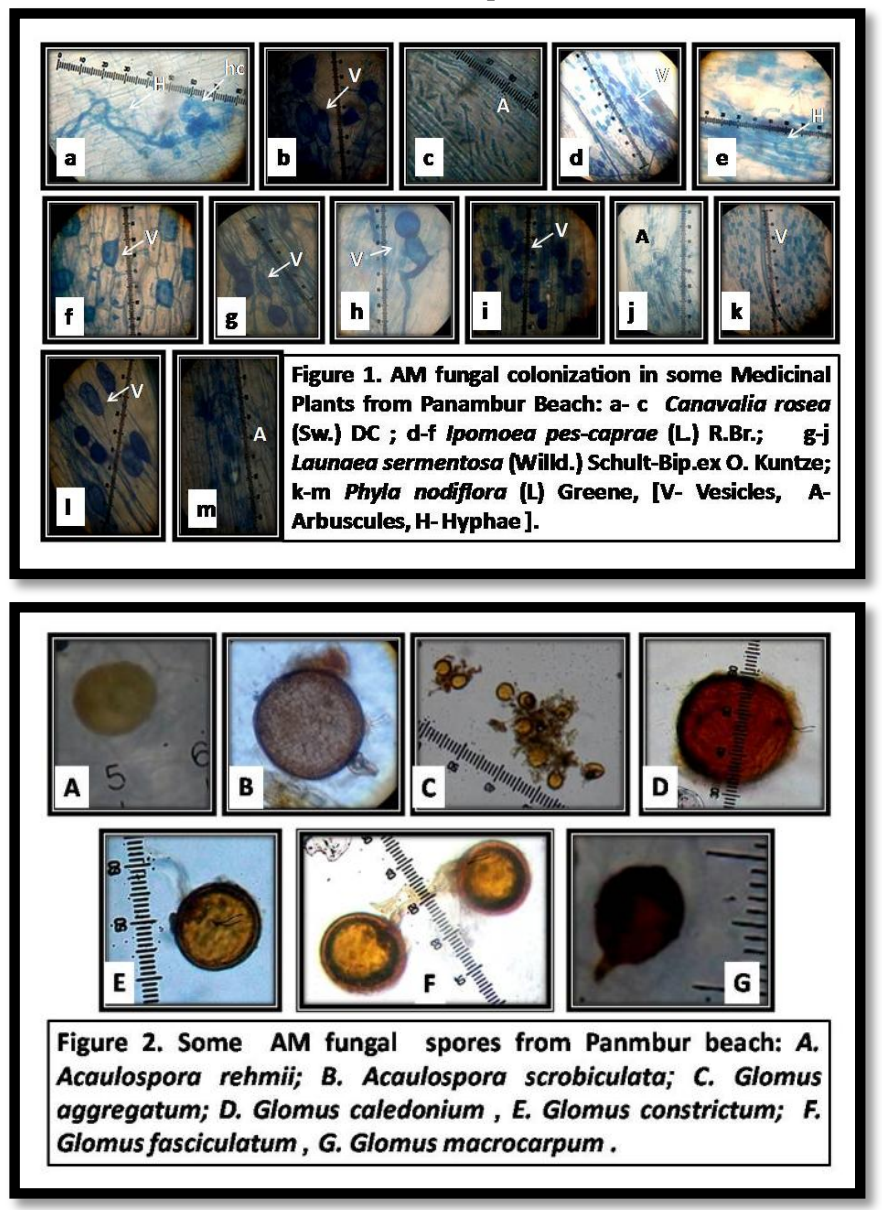

\section{Acknowledgements}

Thanks are due to Dr. (Mrs.) V. I. Katchi, Principal, BCA, Mumbai for providing laboratory facility, and also to Dr. J. Sangeetha, Society for Applied Biotechnology Krishnagiri, Tamil Nadu for field assistance during study. 


\section{References}

[1] Anon, 1979. Gazetteer of the Union Territory Goa, Daman, Diu (ed. Gune, V.T.), 1-1023.

[2] B. Bhagya and K.R. Sridhar, Ethnobiology of costal sand dune legumes of Southwest coast of India, Indian Journal of Traditional Knowledge, 8(4), 2009, 611-620.

[3] B.P. Chaudhari, A.K. Biswal and H.N. Subudhi, Enumeration of some Potential medicinal plants in the district of Cuttack (Oris sa), Biosci Res Bull, 2(1\&2), 1993, 11-16.

[4] C. Pattanaik, C.S. Reddy and N.K. Dhal, Phytochemical study of costal sand dune species of Orissa, Indian Journal of Traditional Knowledge, 7(2), 2008, 263-268.

[5] H.N. Subudhi, B.P. Choudhury, and B.C. Aharya, Potential medicinal plants from Mahanadi delta in the state of Orissa, J Econ Tax Bot, 16(2), 1992, 479-487.

[6] I. Louis, A mycorrhizal survey of plant species colonizing coastal reclaimed land in Singapore, Mycologia, 82, 1990, 772-778.

[7] J. Parekh, and S. Chanda, In-vitro Antimicrobial Activities of Extracts of Launaea procumbens Roxb. (Labiateae), Vitis vinifera L. (Vitaceae) and Cyperus rotundus L. (Cyperaceae) African Journal of Biomedical Research, 9, 2006, 89 -93.

[8] J.M. Phillips, and D. S. Hayman, Improved procedure for clearing roots and staining parasitic and vesicular arbuscular mycorrhizal fungi for rapid assessment of infection, Trans. Br. Mycol. Soc., 55, 1970, $158-161$.

[9] J.W. Gerdemann and T.H. Nicolson, Spores of mycorrhizal Endogone species extracted from soil by wet sieving and decanting, Trans. Br. Mycol. Soc., 46, 1963, 235-244.

[10] K.M. Chetty, K. Sivaji, K.T. Rao, Flowering Plants of Chittoor District Andhra Pradesh, India $1^{\text {st }}$ Ed., (Student Offset Printers, Tirupati, 2008)

[11] K.R. Beena, A.B. Arun and N.S. Raviraja, Association of arbuscular mycorrhizal fungi with plants of coastal sand dunes of west coast of India, Tropical Ecology, 42(2), 2001, 213-222.

[12] K.R. Beena, N.S. Raviraja, and K.R. Sridhar, Association of arbuscular mycorrhizal fungi with Launaea sarmentosa on maritime sand dunes of west coast of India, Kavaka, 25, 1997, 53-60.

[13] K.R. Beena, N.S. Raviraja, A.B. Arun, and K.R. Sridhar, Diversity of arbuscular mycorrhizal fungi on the coastal sand dunes of west coast of India, Current Science, 79(10), 2000, 1459-1466.

[14] M. Giovannetii and B. Mosse, An evaluation of techniques for measuring vesicular - arbuscular mycorrhizal infection in roots, New Phytol. 84, 1980, 489 - 500.

[15] N. Sen, TKDL- A safeguard for Indian traditional knowledge. Curr Sci, 82, 2002, 1070-1071.

[16] N.C. Schenk and Y. Perez, Manual for the identification of VA - Mycorrhizal fungi, $3^{\text {rd }}$ Ed, (University of Florida, Gainesville, Florida, 1990).

[17] P.J. Lee and R.E. Koske, Gigaspora gigantea seasonal abundance and aging of spores in a sand dune, Mycol Res, 98, 1994, 453-457.

[18] R.A. Khan, M.R. Khanand, S. Sahreen, Evaluation of Launaea procumbens use in renal disorders: A rat model, Journal of Ethnopharmacology 128 (2), 2010, 452-461.

[19] R.E. Koske and J.N. Gemma, Arbuscular mycorrhizal fungi in Hawaiian sand dunes: Islands of Kaua'I, Pacific Science ,50, 1996, 3645 .

[20] R.E. Koske and J.N. Gemma, A modified procedure for staining roots to detect VA mycorrhizas. Mycol Res, 92, 1989, 486-

[21] R.E. Koske and J.N. Gemma, VA mycorrhizae in strand vegetation of Hawaii: Evidence for long distance co-dispersal of plants and fungi, Am. J. Bot., 77, 1990, 466-474.

[22] R.E. Koske and W.R. Polson, Are VA mycorrhizae required for sand dune stabilization? Bioscience 34, 1984, 420-424.

[23] S. Wasuwat, Extract of Ipomoea pes-caprae (Convolvulaceae) antagonistic to Histamine and Jelly-fish Poison, Nature, 225, 1970, 758.

[24] V. Jaiswal and B.F. Rodrigues, Occurrence and distribution of arbuscular mycorrhizal fungi in coastal sand dune vegetation of Goa, Current Science, 80, 2001, 826-827.

[25] V. Mohankumar, S. Ragupathy, C.B. Nirmala, and A. Mahadevan, Distribution of vesicular arbuscular mycorrhizae (VAM) in the sandy beach soils of Madras coast, Current Science, 57, 1988, 367-368.

[26] V.R. Kamble, B.K. Sayed and N. Qureshi, Screening of CSDPs for AM Fungal Association from Arnala and Kalamb Beach Maharashtra, IOSR Journal of Pharmacy and Biological Sciences, 2(4), 2012, 44-47.

[27] V.. Kamble, D.G. Agre, and H. Rahate, Arbuscular Mycorrhizal in some medicinal plants found in sand dunes from Revdanda coast of Maharashtra, Proc. $1^{\text {st }}$ Nat Symp. of SAB on Innovative and Modern Technologies for Agricultural Productivity, Food security and Environment Management, Mangalore, India, 2011, 147-148.

[28] Y.N. Singh, T. Ikahihifo, M. Panuve and Slatter, Folk medicine in Tonga: a study of the use of herbal medicines for obstetric and gynaecological conditions and disorders. Journal of Ethnopharmacology, 12, 1984, 305. 